\title{
Air pollution, oxidative stress, and exacerbation of autoimmune diseases
}

\author{
ANNA GAWDA, GRZEGORZ MAJKA, BERNADETA NOWAK, JANUSZ MARCINKIEWICZ
}

Chair of Immunology, Jagiellonian University, Collegium Medicum, Krakow, Poland

\begin{abstract}
A number of epidemiological studies have shown a strong association between exposure to ambient airborne particulate matter $(P M 2.5, P M<1.0)$ and lung or cardiovascular diseases characterised by high mortality and morbidity. However, much less is known about the role of air pollution in the pathogenesis of autoimmune diseases, which constitutes a significant problem in modern society.

This paper summarises the state of current research regarding the influence of PM on the development and/or progression of autoimmune diseases. A brief review of the great body of research concerning pathogenesis of autoimmune disorders is presented. Then, the scope of our review is narrowed to the research related to the impact of particulate matter on oxidative and nitrosative stress, as well as exacerbation of chronic inflammation, because they can contribute to the development of autoimmune diseases. Moreover, we discuss the impact of various components of PM (metal, organic compounds) on PM toxicity and the ability to generate oxidants.
\end{abstract}

Key words: inflammation, oxidative stress, air pollution, particulate matter, autoimmune disease, nitrosative stress.

(Centr Eur J Immunol 2017; 42 (3): 305-312)

\section{Introduction}

The detrimental health effect of the exposure to particulate matter (PM) present in air pollution has been documented in numerous studies [1,2]. Epidemiological evidence indicates that poor air quality contributes to increased morbidity and mortality due to several reasons. Primarily, chronic exposure to PM increases the risk and is associated with progression of lung and cardiovascular diseases [3]. Production of oxidants, either directly by components of PM or by the host response to air pollution, seems to be the major biological effect responsible for tissue injury, and a local as well as systemic inflammatory response [4]. The question arises whether oxidative stress induced by exposure to PM contributes to an increased risk and/or pathogenesis of autoimmune diseases. It is not clear yet whether composition (metal vs. organic components) and/or size of air pollution particles (PM 2.5 vs. PM < 1.0) affects their toxicity and capacity to induce inflammation and immune response to autoantigens.

The immune system - consisting of the fine-tuned network of humoral and cellular components - provides protection against microbial pathogens. The unique ability to discriminate between 'self' and 'non-self' allows this defensive network to eliminate the invading microorganisms while maintaining tolerance towards autoantigens [5].
However, there are cases in which the system fails, and its malfunctioning contributes to pathological processes such as autoimmune diseases (ADs). Prolonged activation of the immune system resulting in chronic inflammation and tissue damage with following involvement of the adaptive immune system is typically observed in most ADs [6].

Autoimmune diseases have a strong genetic background involved [7,8], but the impact of environmental factors must not be underestimated. Infectious agents, drugs as well as physical agents such as cold exposure or air pollution, have been considered as risk factors for either development or exacerbation of these conditions [6].

In this short review, we focus on the pathogenesis of ADs associated with oxidative stress in the correlation with particulate matter (present in air pollution), which can provide an environmental trigger for autoimmune processes.

\section{Autoimmune diseases}

Autoimmune diseases are chronic pathogenic conditions embodying a heterogeneous group of disorders associated with the loss of immunological tolerance to self-antigens [8]. Affecting ca. 5\% of the world population, they are the fourth leading cause of disability for women [9], who are more predisposed to suffer from them $(80 \%$ of AD patients being female [10]).

Correspondence: Prof. Janusz Marcinkiewicz, Chair of Immunology, Jagiellonian University, Collegium Medicum, Czysta 18,

31-121 Krakow, Poland, e-mail: mmmarcin@cyf-kr.edu.pl

Submitted: 28.03.2017; Accepted: 1.06.2017 
The common feature that defines autoimmune diseases is the breakdown of immune tolerance, leading to the development of the adaptive immune response to self-antigens. The hallmarks of the ADs are: the presence of defined autoantigens, production of autoantibodies, and activation of autoreactive CD4+ T helper cells and self-reactive $\mathrm{CD} 8+$ cytotoxic $\mathrm{T}$ cells along with the engagement of the innate immune systems components, such as phagocytic cells (macrophages and neutrophils) [11]. Macrophages take part in tissue damage by releasing reactive oxygen (hydrogen peroxide, superoxide anion) and nitrogen species (nitric oxide). Pro-inflammatory cytokines secreted by macrophages recruit neutrophils and $\mathrm{T}$ cells to the site of inflammation [8]. Moreover, macrophages can drive the autoimmune process by phagocytosis of apoptotic/necrotic cells serving as a potential source of self-antigens that can be subsequently presented to the auto-reactive T cells.

Autoimmune diseases are usually classified into two groups, depending on whether the effect is organ-specific or systemic [8]. Systemic autoimmune disorders, such as rheumatoid arthritis (RA) or systemic lupus erythematosus (SLE), are characterised by multi-organ involvement, which probably arises from the systemic distribution of the auto-antigens.

Organ-specific autoimmune disorders develop when the immune response is directed against auto-antigens located in a specific organ. Diabetes mellitus type 1, multiple sclerosis (MS), primary biliary cirrhosis (PBC), Hashimoto's thyroiditis or Graves' disease deserve to be mentioned among numerous organ-specific autoimmune diseases. What is important, the autoimmune processes which take part in the development of the chronic inflammatory diseases mentioned above demonstrate organ-specific characteristics.

The involvement of the immune system has implied theories that specific proteins, which play a crucial role in the immunological response, may take part in the pathogenesis of ADs. Some HLA haplotypes are considered to be particularly important for presentation of autoantigens in the autoimmune process. Thus, concurrent expression of both HLA-DR2 and HLA-DR3 predisposes an individual to development of systemic lupus erythematosus (SLE). Type 1 diabetes mellitus (DM) has a particularly strong correlation with HLA-DR3, -DR4, -DQ2, and -DQ8 [12, 13]. People with certain alleles of HLA-DR4 are notably predisposed to rheumatoid arthritis (RA) [14]. Although genetic predilection plays a major role in autoimmunity (over 200 loci have been implicated in autoimmune disorders), genetics cannot fully explain the patterns of these diseases.

Infections $[15,16]$ and immune adjuvants $[17,18]$ are thought to play a crucial role in AD development or exacerbation in genetically susceptible individuals [19, 20]. Our current studies focus on elucidating the impact of the inorganic chemical substances (such as transition metal oxides) present in air pollution on the autoimmune processes.

\section{Oxidative/nitrosative stress}

Prolonged activation of the innate immune system and chronic inflammatory response are both features of ADs that are commonly associated with increased concentration of reactive species of oxygen and nitrogen that can significantly contribute to the development of these pathogenic conditions.

A relatively new term of oxidative stress refers to the imbalance between oxidant and antioxidant molecules that can potentially lead to a tissue damage due to the excess of the former [21]. Such a situation occurs when production of reactive oxygen species exceeds their elimination rate regulated by the antioxidant system. Similarly, nitrosative stress has been described as a phenomenon in which the reactive nitrogen species in excess contribute to the pathogenic processes [22].

The terms reactive oxygen and nitrogen species encompass molecules that are natural by-products of the normal cell metabolism. Physiologically, these molecules are involved in numerous processes - they are important for respiratory burst of phagocytic cells, cellular signalling, and thyroid hormone synthesis [23].

Most of the reactive oxygen species (ROS) are generated by electron leak during ATP production in mitochondria [24], but they can also be generated by NAPDH oxidase and other oxidases. Superoxide anion, hydrogen peroxide and hydroxyl radical are the three most important ROS in biological systems. Other reactive molecules such as $\mathrm{HOCl}$ (important for microbicidal activity of phagocytes) can be generated by reaction of hydrogen peroxide with chloride anion catalysed by myeloperoxidase present in azurophilic granules of neutrophils [25, 26].

Nitric oxide (NO) is the primary source of all reactive nitrogen species (RNS) present in the biological system $[27,28]$. NO is a small signalling molecule generated by nitric oxide synthase, which plays a major role in vasodilation and neurotransmission but is also involved in the antimicrobial response of the phagocytes. The nitric oxide potential in the pathogenesis of diseases stems from its reaction with superoxide, and results in formation of peroxynitrite, which is a potent nitrating and oxidising agent $[29,30]$.

Under physiological conditions, the concentration of reactive oxygen and reactive nitrogen species (RONS) is controlled by the scavenging system involving molecular and enzymatic antioxidants, which serve to maintain cellular redox balance [31]. A decrease of RONS level negatively affects cellular signalling [32], whereas high levels of RONS have been implicated in the pathogenesis of ADs $[33,34]$. The mechanism behind this observation might be related not only to the initiation of pro-inflammatory 
response, but also to the structural modification of autoantigen resulting in a generation of novel, potentially auto-reactive epitopes [35]. These alterations usually occur upon RONS-dependent peroxidation of lipids within the cells, which leads to formation of highly reactive aldehydes, such as malondialdehyde and 4-hydroxynonenal. These molecules can form covalent bonds with proteins and alter both their structure and biological functions. Products of oxidative modification present in blood are considered potential biomarkers of the systemic oxidative stress, inflammation, and ADs [36].

\section{Particulate matter present in air pollution}

Air pollution is a mixture of gases (carbon monoxide, nitrates, sulphur dioxide, and ozone), aerosols, and particulate matter (solid and liquid particles) [37, 38]. There are two main subtypes of atmospheric particulate matter: fine particles and ultrafine particles. Fine particles have a diameter smaller than $2.5 \mu \mathrm{m}$ (PM 2.5), while the ultrafine particles have a diameter smaller than $0.1 \mu \mathrm{m}$ [3].

Roughly-speaking, particulate matter (PM) is a complex mixture of solid and liquid particles that is released into the air during combustion of coal, wood, gasoline, diesel, or fossil fuels, as well as from natural sources (road dust, fires, volcanic emissions, etc.) [39]. Most of the ultrafine particles are composed of sulphates and nitrates, but hydrocarbons, benzene, toluene, metals, and other substances can also be present in the adsorbed molecules, which can be inhaled by humans [2].

Human lungs make up the largest surface area exposed to the environmental factors present in the air. The human respiratory system possesses its own defensive mechanisms involving components of both innate (mechanical mucus barrier, mucociliary clearance, and antimicrobial factors) and acquired immunity (reaction to specific antigens with T-cell involvement) [40]. However, some oxidant substances constituting air pollution are likely to influence the physiology of the cells and either trigger or exacerbate the inflammatory reaction. Progressing industrialisation and the growing number of motor vehicles put people at risk to exposure of high concentrations of such substances that have the capability to percolate to the upper respiratory tract.

\section{Air pollution vs. autoimmune diseases}

Several epidemiological studies have provided substantial evidence for the relationship between air pollution and development of autoimmune diseases [41, 42]. Herein, we present certain ADs and analyse the correlation between disease incidence and the presence of particulate matter in inhaled air.

SLE is a chronic autoimmune disease characterised by the presence of autoantibodies, formation of immune com- plexes, and activation of autoreactive $\mathrm{B}$ and $\mathrm{T}$ lymphocytes $[43,44]$. Occupational exposure to silica, pesticides, solvents, and other inhaled substances has been linked to its development [45-49]. The incidence of SLE has not been found to correlate with particulate matter present in the air. However, it seems likely that PM 2.5 may exacerbate the onset of the disease because they were attributed to a significant increase of the level of anti-dsDNA antibodies, and the presence of the renal casts in SLE patients [50].

Diabetes mellitus type 1 can be characterised by total deficiency of insulin release by the $\beta$-cells of pancreas, which are destroyed in the autoimmune process [51]. The root cause of DM type 1 remains unknown, but some studies suggest that a combination of genetic and environmental factors is involved. Exposure to ozone, sulphates, and other pollutants present in the air has been associated with type 1 diabetes in children $[52,53]$. Air pollution was found to increase the risk of acute complications of diabetes demanding hospitalisation [54]. Nevertheless, there are only a few reports suggesting that air pollution increases mortality among diabetics [55-57].

Rheumatoid arthritis is a systemic autoimmune disease characterised by multi-system inflammation [58-60]. Both genetic and environmental factors have been implicated in its development; however, the mechanism through which the environmental triggers might affect the disease has not been elucidated [61]. Both tobacco smoking and exposure to silica have been associated with higher risk of developing RA [62-66]. High concentration of PM 2.5 has been shown to increase the risk of juvenile idiopathic arthritis among young children by $60 \%$ [67]. Similarly, exposure to PM 2.5 has been associated with the prevalence of systemic RA $[61,68]$. Furthermore, the analyses performed by the Nurses' Health Study in 2009 [69] suggest that pollution emissions from road traffic may be an environmental factor responsible for exacerbation of RA.

Association between air pollution and autoimmunity has also been found for multiple sclerosis (MS) - increased concentration of pollutants in the air (PM10 as well as $\mathrm{SO}_{2}$ $+\mathrm{NO}_{2}+\mathrm{NO}$ ) was correlated with relapses of the disease [42]. The potential association between MS occurrence and air pollution was implied following the study in the state of Georgia, US [70]. These findings were later confirmed by similar studies performed in Iran, Serbia, France, and Italy - demonstrating that MS occurrence and hospitalisation was associated with exposure to air pollutants such as $\mathrm{PM} 10, \mathrm{SO}_{2}, \mathrm{NO}_{2}$, and NOx [71-74].

\section{From air pollution to autoimmune process}

The mechanisms behind the relationship between poor air quality and AD prevalence and exacerbation are still unclear. While the local impact of inhaled air pollution particles on lung injury might seem obvious, it is not evident how they can affect other remote tissues to initiate 
autoimmune processes (how they can prime autoimmune processes in other remote tissues). Several hypotheses suggest activation of the systemic inflammatory response via oxidative/nitrosative stress, as well as the enhanced presentation of oxidative-modified autoantigens $[75,76]$.

When PMs are inhaled, some oxidants are generated locally in lung alveoli, where they may cause local chronic inflammation. However, the correlation between air pollution, the lung, and chronic inflammation has not been well examined [36]. The key to explain the role of lung in systemic inflammation lies in understanding the mechanism of modification of the biomolecules produced by inhaled oxidants (PM components), or generated by inflammatory cells in the upper and lower airways (alveolar macrophages) [77, 78]. Oxidised biomolecules are more susceptible to degradation, but they can also inhibit the removal of oxidatively modified proteins via the proteasome system [79].

The effect of inhaled nanoparticles (PM) on human health depends on both individual predisposition (such as genetic factors) and PM properties [80]. The opinion that a particle's toxicity depends on its size, shape, and composition is broadly accepted [81]. Importantly, the oxidative stress can result from Fenton-type reactions catalysed by the transition metal present in particles, such as $\mathrm{Fe}, \mathrm{V}, \mathrm{Cr}, \mathrm{Co}, \mathrm{Ni}, \mathrm{Cu}, \mathrm{Zn}$, and Ti [82], but other metals and non-metals can also exert negative effects on the cells. For example, silica particles are toxic to macrophages [8385 ] and induce cell death causing exposure of intracellular self-antigens to immune cells $[86,87]$. In murine models of silica exposure an increase in the production of autoantibodies and formation of autoantibody immune complexes was observed [88, 89], as well as an increase in numbers of B-lymphocytes and CD4 T cells [90]. All these factors might contribute to chronic lung inflammation and have been reported as possible risk factors for development of autoimmune diseases, such as RA and SLE [91].

It has been shown that environmental exposure to asbestos particularly increases the risk of autoimmune diseases $[92,93]$. In turn, exposure to iron and other transition metals can result in generation of reactive oxygen species on the lung cells surface, which may cause injury and lead to formation of scar tissue [94].

Numerous studies have revealed a negative impact of inhalation of air pollutants on human health. In general, particulate matter (PM) affects the upper bronchi, and this may lead to pulmonary inflammation [95]. Nanoparticles are considered even more dangerous than large size particles because they are more difficult to remove from the human body by the organism itself. Due to their small size, nanoparticles penetrate easily via the respiratory tract into the biological structures and disrupt their functions by driving oxidative stress and contributing to tissue inflammation [80].
Inhalation of nanoparticles has been shown to stimulate alveolar macrophages, creating conditions for development of an acute systemic inflammatory response [37, 96, 97]. Airway inflammation, a major short-term effect of inhalation of the particles present in the polluted air [98], is characterised by an increased secretion of pro-inflammatory mediators like interleukin-8 [99] and granulocyte macrophage-colony stimulating factor (GM-CSF), as well as by neutrophil influx [100, 101]. Inflammatory cells, neutrophils, and macrophages, generate a variety of reactive oxygen and nitrogen species and release various proteases that damage lung tissue [22]. Then, following the fine and ultrafine particles' passage into the blood, exposure to PM can potentially trigger a systemic inflammatory process [95] via induction of ROS production and pro-inflammatory cytokine release $[102,103]$.

It seems plausible that generation of soluble inflammatory mediators in the lungs upon PM inhalation might have a systemic impact. Systemic oxidative stress [104, 105], stimulation of the bone marrow [97, 106, 107], and increased levels of cytokines and leukocytes in blood have all been associated with exposure to air pollutants $[108$, 109]. Furthermore, air pollution has been shown to induce maturation of antigen presenting cells by inducing expression of costimulatory molecules [110-116]. Particulate matter present in the air can also act as an adjuvant and induce immune response against otherwise non-immunogenic antigens in several animal models [101, 117-119]. Animal studies have also provided evidence that exposure to particulate matter can have glycaemic consequences in a gestational diabetes mellitus rat model [120].

Therefore, air pollution could affect the autoimmune processes in multiple ways. Induction of oxidative/nitrosative stress can lead to production of autoantigens (via oxidative modification) and additionally to the stimulation of the release of soluble inflammatory mediators (cytokines) that can trigger maturation of antigen-presenting cells [75]. APCs migrating to the lymph nodes could thus present the self-antigens to the lymphocytes that had evaded the mechanisms of central tolerance. Upon establishment of the autoimmune reaction, pro-inflammatory cytokines that are released following continuous inhalation of the pollutants could additionally exacerbate the process.

\section{Conclusions}

Autoimmune diseases are among the most crucial challenges of current medicine. They still cause chronic disability and mortality of patients with pulmonary and cardiovascular diseases. Currently, it has been accepted that particulate matter can contribute to autoimmunity by complex interactions between genetic, environmental, and epigenetic factors. However, the exact molecular mechanisms by which chemicals contained in air pollution affect autoimmunity are still unknown. Particulate matter present 
in air pollution can induce oxidative stress and cell death, both by apoptosis and necrosis of human cells leading to aggravation of chronic inflammation, i.e. the tissue damaging reaction observed in autoimmune diseases. Therefore, identification of strong inducers of oxidative stress among components of PM seems to be crucial for their neutralisation and elimination from the ambient environment.

This work was financed by the National Science Centre (Poland, project number 2015/16/WST5/00005). The authors declare no conflict of interest.

\section{References}

1. Liu S-K, Cai S, Chen Y, et al. (2016): The effect of pollutional haze on pulmonary function. J Thorac Dis 8: E41-E56.

2. Valavanidis A, Fiotakis K, Vlachogianni T (2008): Airborne particulate matter and human health: Toxicological assessment and importance of size and composition of particles for oxidative damage and carcinogenic mechanisms. J Environ Sci Health C Environ Carcinog Ecotoxicol Rev Part C 26: 339-362.

3. Pope CA, Burnett RT, Thurston GD, et al. (2004): Cardiovascular mortality and long-term exposure to particulate air pollution. Circulation 109: 71 .

4. Ghio AJ, Carraway MS, Madden MC (2012): Composition of air pollution particles and oxidative stress in cells, tissues, and living systems. J Toxicol Environ Health B 15: 1-21.

5. Kanazawa N, Tchernev G, Wollina U (2014): Autoimmunity versus autoinflammation - friend or foe? Wien Med Wochenschr 164: 274-277.

6. Doria A, Zen M, Bettio S, et al. (2012): Autoinflammation and autoimmunity: Bridging the divide. Autoimmun Rev 12: 22-30.

7. Touitou I (2012): New genetic interpretation of old diseases. Autoimmun Rev 12: 5-9.

8. Anaya J-M (2012): Common mechanisms of autoimmune diseases (the autoimmune tautology). Autoimmun Rev 11: 781-784.

9. Oliver JE, Silman AJ (2009): Why are women predisposed to autoimmune rheumatic diseases? Arthritis Res Ther 11: 252.

10. Fairweather D, Frisancho-Kiss S, Rose NR (2008): Sex differences in autoimmune disease from a pathological perspective. Am J Pathol 173.

11. Jäger A, Kuchroo VK (2010): Effector and regulatory T-cell subsets in autoimmunity and tissue inflammation. Scand J Immunol 72: 173-184.

12. Chowdhary VR, Dai C, Tilahun AY, et al. (2015): A central role for HLA-DR3 in anti-Smith antibody responses and glomerulonephritis in a transgenic mouse model of spontaneous lupus. J Immunol 195: 4660-4667.

13. Pociot F, Lernmark L Genetic risk factors for type 1 diabetes. Lancet 387: 2331-2339.

14. Ray S, Sonthalia N, Kundu S, Ganguly S (2012): Autoimmune disorders: An overview of molecular and cellular basis in today's perspective. Journal of Clinical \& Cellular Immunology.

15. Kivity S, Agmon-Levin N, Blank M, Shoenfeld Y (2009): Infections and autoimmunity - friends or foes? Trends in Immunology 30: 409-414.
16. Adams DD, Knight JG, Ebringer A (2010): Autoimmune diseases: Solution of the environmental, immunological and genetic components with principles for immunotherapy and transplantation. Autoimmunity Reviews 9: 525-530.

17. Shoenfeld Y, Agmon-Levin N (2011): 'Asia' - autoimmune/ inflammatory syndrome induced by adjuvants. J Autoimmun 36: 4-8.

18. Israeli E, Agmon-Levin N, Blank M, Shoenfeld Y (2009): Adjuvants and autoimmunity. Lupus 18: 1217-1225.

19. Sellner J, Kraus J, Awad A et al. (2011): The increasing incidence and prevalence of female multiple sclerosis - a critical analysis of potential environmental factors. Autoimmunity Reviews 10: 495-502.

20. Gualtierotti R, Biggioggero M, Penatti AE, Meroni PL (2010): Updating on the pathogenesis of systemic lupus erythematosus. Autoimmunity Reviews 10: 3-7.

21. Sies H (1997): Oxidative stress: Oxidants and antioxidants. Exp Physiol 82: 291-295.

22. Klandorf H, Van Dyke K: Oxidative and nitrosative stresses: Their role in health and disease in man and birds. In: Oxidative Stress - Molecular Mechanisms and Biological Effects. Luschchak V, Semchyshyn HM (eds.). InTech, Rijeka 2012; 47-60.

23. Wang X, Tao L, Hai CX (2012): Redox-regulating role of insulin: The essence of insulin effect. Mol Cell Endocrinol 349: 111-127.

24. Balaban RS, Nemoto S, Finkel T (2005): Mitochondria, oxidants, and aging. Cell 120: 483-495.

25. Taniyama Y, Griendling KK (2003): Reactive oxygen species in the vasculature. Molecular and Cellular Mechanisms 42: 1075-1081.

26. Klebanoff SJ, Kettle AJ, Rosen H et al. (2013): Myeloperoxidase: A front-line defender against phagocytosed microorganisms. J Leukoc Biol 93: 185-198.

27. Patel RP, Mcandrew J, Sellak H et al. (1999): Biological aspects of reactive nitrogen species. Biochim Biophys Acta Bioenergetics 1411: 385-400.

28. Marcinkiewicz E, Marcinkiewicz J, Chłopicki S (2004): Nitric oxide - a pro-inflammatory and anti-inflammatory mediator. Central European Journal of Immunology 28: 74-78.

29. Weinberg JB, Granger DL, Pisetsky DS et al. (1994): The role of nitric oxide in the pathogenesis of spontaneous murine autoimmune disease: Increased nitric oxide production and nitric oxide synthase expression in MRL-lpr/lpr mice, and reduction of spontaneous glomerulonephritis and arthritis by orally administered NG-monomethyl-L-arginine. The Journal of Experimental Medicine 179: 651-660.

30. Wang G, Pierangeli SS, Papalardo E, et al. (2010): Markers of oxidative and nitrosative stress in systemic lupus erythematosus: Correlation with disease activity. Arthritis Rheum 62: 2064-2072.

31. Xu X, Liu C, Xu Z, et al. (2011): Long-term exposure to ambient fine particulate pollution induces insulin resistance and mitochondrial alteration in adipose tissue. Toxicol Sci 124: 88-98.

32. Wang J, Yi J (2008): Cancer cell killing via ROS: To increase or decrease, that is the question. Cancer Biol The 7: 18751884.

33. Kurien BT, Hensley K, Bachmann M, Scofield RH (2006): Oxidatively modified autoantigens in autoimmune diseases. Free Radic Biol Med 41: 549-556.

34. Frostegĺrd J, Svenungsson E, Wu R, et al. (2005): Lipid peroxidation is enhanced in patients with systemic lupus ery- 
thematosus and is associated with arterial and renal disease manifestations. Arthritis Rheum 52: 192-200.

35. Di Dalmazi G, Hirshberg J, Lyle D, et al. (2016): Reactive oxygen species in organ-specific autoimmunity. Autoimmunity Highlights 7: 11.

36. Gomez-Mejiba SE, Zhai Z, Akram H, et al. (2009): Inhalation of environmental stressors \& chronic inflammation: Autoimmunity and neurodegeneration. Mutat Res Genetic Toxicology and Environmental Mutagenesis 674: 62-72.

37. Farhat SCL, Silva CA, Orione MM, et al. (2011): Air pollution in autoimmune rheumatic diseases: A review. Autoimmun Rev 11: 14-21.

38. Brook RD, Franklin B, Cascio W, et al. (2004): Air pollution and cardiovascular disease. Circulation 109: 2655-2671.

39. Sierra-Vargas MP, Teran LM (2012): Air pollution: Impact and prevention. Respirology 17: 1031-1038.

40. Grzela K, Zagórska W, Grzela T (2012): Mechanisms of the innate immunity in the respiratory system. Centr Eur J Immunol 37: 280-285.

41. Doran MF, Pond GR, Crowson CS et al. (2002): Trends in incidence and mortality in rheumatoid arthritis in Rochester, Minnesota, over a forty-year period. Arthritis Rheum 46: 625631.

42. Oikonen M, Laaksonen M, Laippala P, et al. (2003): Ambient air quality and occurrence of multiple sclerosis relapse. Neuroepidemiology 22: 95-99.

43. Crispin JC, Hedrich CM, Tsokos GC (2013): Gene-function studies in systemic lupus erythematosus. Nat Rev Rheumatol 9: 476-484.

44. Tsokos GC (2011): Systemic lupus erythematosus. N Engl J Med 365: 2110-2121.

45. Hatron PY, Plouvier B, François M, et al. (1982): Association of lupus erythematosus and silicosis. Rev Med Interne 3: 245-246.

46. Parks CG, Cooper GS, Nylander-French LA, et al. (2002): Occupational exposure to crystalline silica and risk of systemic lupus erythematosus: A population-based, case-control study in the southeastern United States. Arthritis Rheum 46: 1840-1850.

47. Balluz L, Philen R, Ortega L, et al. (2001): Investigation of systemic lupus erythematosus in Nogales, Arizona. Am J Epidemiol 154: 1029-1036.

48. Cooper GS, Parks CG, Treadwell EL, et al. (2004): Occupational risk factors for the development of systemic lupus erythematosus. J Rheumatol 31: 1928-1933.

49. Cooper GS, Wither J, Bernatsky S, et al. (2010): Occupational and environmental exposures and risk of systemic lupus erythematosus: Silica, sunlight, solvents. Rheumatology (Oxford) 49: 2172-2180.

50. Bernatsky S, Hudson M, Panopalis P, et al. (2009): The cost of systemic sclerosis. Arthritis Care Res 61: 119-123.

51. Olokoba AB, Obateru OA, Olokoba LB (2012): Type 2 diabetes mellitus: A review of current trends. Oman Medical Journal 27: 269-273.

52. Hathout EH, Beeson WL, Nahab F, et al. (2002): Role of exposure to air pollutants in the development of type 1 diabetes before and after $5 \mathrm{yr}$ of age. Pediatric Diabetes 3: 184-188.

53. Hathout EH, Beeson WL, Ischander M, et al. (2006): Air pollution and type 1 diabetes in children. Pediatric Diabetes 7: 81-87.

54. Dales RE, Cakmak S, Vidal CB, Rubio MA (2012): Air pollution and hospitalization for acute complications of diabetes in Chile. Environment International 46: 1-5.
55. Brook RD, Jerrett M, Brook JR, et al. (2008): The relationship between diabetes mellitus and traffic-related air pollution. J Occup Environ Med 50: 32-38.

56. Kan H, Jia J, Chen B (2004): The association of daily diabetes mortality and outdoor air pollution in Shanghai, China. J Environ Health 67: 21-26.

57. Pearson JF, Bachireddy C, Shyamprasad S, et al. (2010): Association between fine particulate matter and diabetes prevalence in the U.S. Diabetes Care 33: 2196-2201.

58. Callaghan R, Prabu A, Allan RB, et al. (2007): Direct healthcare costs and predictors of costs in patients with primary Sjögren's syndrome. Rheumatology (Oxford) 46: 105-111.

59. Bernatsky S, Renoux C, Suissa S (2010): Demyelinating events in rheumatoid arthritis after drug exposures. Ann Rheum Dis 69: 1691-1693.

60. Aghdassi E, Zhang W, St-Pierr Y, et al. (2011): Healthcare cost and loss of productivity in a Canadian population of patients with and without lupus nephritis. J Rheumatol 38: 658-666.

61. Bernatsky S, Smargiassi A, Johnson M, et al. (2015): Fine particulate air pollution, nitrogen dioxide, and systemic autoimmune rheumatic disease in Calgary, Alberta. Environ Res 140: 474-478.

62. Arnson Y, Shoenfeld Y, Amital H (2010): Effects of tobacco smoke on immunity, inflammation and autoimmunity. J Autoimmun 34: J258-J265.

63. Olsson ĹR, Skogh T, Wingren G (2001): Comorbidity and lifestyle, reproductive factors, and environmental exposures associated with rheumatoid arthritis. Ann Rheum Dis 60: 934939.

64. Silman AJ, Newman J, Macgregor AJ (1996): Cigarette smoking increases the risk of rheumatoid arthritis: Results from a nationwide study of disease-discordant twins. Arthritis Rheum 39: 732-735.

65. Sluis-Cremer GK, Hessel PA, Hnizdo E, Churchill AR (1986): Relationship between silicosis and rheumatoid arthritis. Thorax 41: 596-601.

66. Klockars M, Koskela RS, Järvinen E, et al. (1987): Silica exposure and rheumatoid arthritis: A follow up study of granite workers 1940-81. Br Med J (Clin Res Ed) 294: 997-1000.

67. Zeft AS, Prahalad S, Lefevre S, et al. (2009): Juvenile idiopathic arthritis and exposure to fine particulate air pollution. Clin Exp Rheumatol 27: 877-884.

68. Bernatsky S, Smargiassi A, Barnabe C, et al. (2016): Fine particulate air pollution and systemic autoimmune rheumatic disease in two Canadian provinces. Environ Res 146: 85-91.

69. Hart JE, Laden F, Puett RC, et al. (2009): Exposure to traffic pollution and increased risk of rheumatoid arthritis. Environ Health Perspect 117: 1065-1069.

70. Gregory Ii AC, Shendell DG, Okosun IS, Gieseker KE (2008): Multiple sclerosis disease distribution and potential impact of environmental air pollutants in Georgia. Sci Total Environ 396: 42-51.

71. Heydarpour P, Amini H, Khoshkish S, et al. (2014): Potential impact of air pollution on multiple sclerosis in Tehran, Iran. Neuroepidemiology 43: 233-238.

72. Vojinović S, Savić D, Lukić S, et al. (2015): Disease relapses in multiple sclerosis can be influenced by air pollution and climate seasonal conditions. Vojnosanit Pregl 72: 44-49.

73. Leray E, Le Pabic E, Fermanian C, et al. (2015): Does air pollution influence risk of relapse in multiple sclerosis? Mult Scler 21: 742-743. 
74. Angelici L, Piola M, Cavalleri T, et al. (2016): Effects of particulate matter exposure on multiple sclerosis hospital admission in Lombardy region, Italy. Environ Res 145: 68-73.

75. Ritz SA (2010): Air pollution as a potential contributor to the 'epidemic' of autoimmune disease. Med Hypotheses 74: 110-117.

76. Prokopowicz ZM, Arce F, Biedron R, et al. (2010): Hypochlorous acid: A natural adjuvant that facilitates antigen processing, cross-priming, and the induction of adaptive immunity. J Immunol 184: 824-835.

77. Davies KJA (1995): Oxidative stress: The paradox of aerobic life. Biochemical Society Symposium 61: 1-31.

78. Negre-Salvayre A, Coatrieux C, Ingueneau C, Salvayre R (2008): Advanced lipid peroxidation end products in oxidative damage to proteins. Potential role in diseases and therapeutic prospects for the inhibitors. Br J Pharmacol 153: 6-20.

79. Grune T, Davies KJ (2003): The proteasomal system and HNE-modified proteins. Mol Aspects Med 24: 195-204.

80. Buzea C, Pacheco II, Robbie K (2007): Nanomaterials and nanoparticles: Sources and toxicity. Biointerphases 2: MR17-71.

81. Harrison RM, Yin J (2000): Particulate matter in the atmosphere: Which particle properties are important for its effects on health? Sci Total Environ 249: 85-101.

82. Shi T, Schins RP, Knaapen AM, et al. (2003): Hydroxyl radical generation by electron paramagnetic resonance as a new method to monitor ambient particulate matter composition. Journal of Environmental Monitoring : JEM 5: 550-556.

83. Davis GS, Pfeiffer LM, Hemenway DR (1998): Persistent overexpression of interleukin-1beta and tumor necrosis factor-alpha in murine silicosis. J Environ Pathol Toxicol Oncol 17: 99-114.

84. Davis GS, Holmes CE, Pfeiffer LM, Hemenway DR (2001): Lymphocytes, lymphokines, and silicosis. J Environ Pathol Toxicol Oncol 20: 14.

85. Costantini LM, Gilberti RM, Knecht DA (2011): The phagocytosis and toxicity of amorphous silica. PLoS ONE 6: e14647.

86. Lim Y, Kim JH, Kim KA, et al. (1999): Silica-induced apoptosis in vitro and in vivo. Toxicol Lett 108: 335-339.

87. Joshi GN, Knecht DA (2013): Silica phagocytosis causes apoptosis and necrosis by different temporal and molecular pathways in alveolar macrophages. Apoptosis 18: 271-285.

88. Brown JM, Archer AJ, Pfau JC, Holian A (2003): Silica accelerated systemic autoimmune disease in lupus-prone New Zealand mixed mice. Clin Exp Immunol 131: 415-421.

89. Pfau JC, Brown JM, Holian A (2004): Silica-exposed mice generate autoantibodies to apoptotic cells. Toxicology 195: 167-176.

90. Brown JM, Pfau JC, Holian A (2004): Immunoglobulin and lymphocyte responses following silica exposure in new zealand mixed mice. Inhal Toxicol 16: 133-139.

91. Firestein GS, Mcinnes IB (2017): Immunopathogenesis of rheumatoid arthritis. Immunity 46: 183-196.

92. Noonan CW, Pfau JC, Larson TC, Spence MR (2006): Nested case-control study of autoimmune disease in an asbestos-exposed population. Environ Health Perspect 114: 1243-1247.

93. Bernatsky SM, Pfau JC, Fritzler MJ (2017): Environmental exposures and biomarkers predictive of rheumatoid arthritis and the pathway to precision medicine. J Laboratory and Precision Medicine 2.
94. Taylor DA (2002): Dust in the wind. Environ Health Perspect 110: A80-A87.

95. Nemmar A, Hoet PHM, Vanquickenborne B, et al. (2002): Passage of inhaled particles into the blood circulation in humans. Circulation 105: 411-414.

96. Pope CA, Dockery DW (2006): Health effects of fine particulate air pollution: Lines that connect. J Air Waste Manag Assoc 56: 709-742.

97. Eeden SFV, Hogg JC (2002): Systemic inflammatory response induced by particulate matter air pollution: The importance of bone-marrow stimulation. J Toxicol Environ Health A 65: 1597-1613.

98. Ghio AJ, Huang Y-CT (2004): Exposure to concentrated ambient particles (caps): A review. Inhal Toxicol 16: 53-59.

99. Stenfors N, Nordenhäll C, Salvi SS, et al. (2004): Different airway inflammatory responses in asthmatic and healthy humans exposed to diesel. Eur Respir J 23: 82-86.

100. Behndig AF, Mudway IS, Brown JL, et al. (2006): Airway antioxidant and inflammatory responses to diesel exhaust exposure in healthy humans. Eur Respir J 27: 359-365.

101. Takano H, Ichinose T, Miyabara Y, et al. (1998): Inhalation of diesel exhaust enhances allergen-related eosinophil recruitment and airway hyperresponsiveness in mice. Toxicol Appl Pharmacol 150: 328-337.

102. Salvi, Holgate (1999): Mechanisms of particulate matter toxicity. Clin Exp Allergy 29: 1187-1194.

103. Poniedziałek B, Rzymski P, Wiktorowicz K (2012): In vitro effect of cadmium on the function of human lymphocytes and neutrophils. Centr Eur J Immunol 37: 110-113.

104. Araujo JA, Barajas B, Kleinman M, et al. (2008): Ambient particulate pollutants in the ultrafine range promote early atherosclerosis and systemic oxidative stress. Circ Res 102: 589-596.

105. Barregard L, Sällsten G, Gustafson P, et al. (2006): Experimental exposure to wood-smoke particles in healthy humans: Effects on markers of inflammation, coagulation, and lipid peroxidation. Inhal Toxicol 18: 845-853.

106. Goto Y, Ishii H, Hogg JC, et al. (2004): Particulate matter air pollution stimulates monocyte release from the bone marrow. Am J Respir Crit Care Med 170: 891-897.

107. Fujii T, Hayashi S, Hogg JC, et al. (2002): Interaction of alveolar macrophages and airway epithelial cells following exposure to particulate matter produces mediators that stimulate the bone marrow. Am J Respir Cell Mol Biol 27: 34-41.

108. Liao D, Heiss G, Chinchilli VM, et al. (2004): Association of criteria pollutants with plasma hemostatic//inflammatory markers: A population-based study. J Expo Anal Environ Epidemiol 15: 319-328.

109. Eeden SFV, Tan WC, Suwa T, et al. (2001): Cytokines involved in the systemic inflammatory response induced by exposure to particulate matter air pollutants (PM10). Am J Respir Crit Care Med 164: 826-830.

110. Verstraelen S, Van Den Heuvel R, Nelissen I, et al. (2005): Flow cytometric characterisation of antigen presenting dendritic cells after in vitro exposure to diesel exhaust particles. Toxicology In Vitro 19: 903-907.

111. Becker S, Soukup J (2003): Coarse(PM 2.5-10), fine(PM $2.5)$, and ultrafine air pollution particles induce/increase immune costimulatory receptors on human blood-derived monocytes but not on alveolar macrophages. J Toxicol Environ Health, A 66: 847-859.

112. Bleck B, Tse DB, Curotto De Lafaille MA, et al. (2008): Diesel exhaust particle-exposed human bronchial epithelial 
cells induce dendritic cell maturation and polarization via thymic stromal lymphopoietin. J Clin Immunol 28: 147-156.

113. Hamilton RF, Holian A, Morandi MT (2004): A comparison of asbestos and urban particulate matter in the in vitro modification of human alveolar macrophage antigen-presenting cell function. Exp Lung Res 30: 147-162.

114. Kantengwa S, Jornot L, Devenoges C, Nicod LP (2003): Superoxide anions induce the maturation of human dendritic cells. Am J Respir Crit Care Med 167: 431-437.

115. Alderman CJJ, Shah S, Foreman JC, et al. (2002): The role of advanced oxidation protein products in regulation of dendritic cell function. Free Radic Biol Med 32: 377-385.

116. Rutault K, Alderman C, Chain BM, Katz DR (1999): Reactive oxygen species activate human peripheral blood dendritic cells. Free Radic Biol Med 26: 232-238.

117. Granum B, Gaarder PI, Groeng EC, et al. (2001): Fine particles of widely different composition have an adjuvant effect on the production of allergen-specific antibodies. Toxicol Lett 118: 171-181.

118. Takano H, Yoshikawa T, Ichinose T, et al. (1997): Diesel exhaust particles enhance antigen-induced airway inflammation and local cytokine expression in mice. Am J Respir Crit Care Med 156: 36-42.

119. Van Zijverden M, Van Der Pijl A, Bol M, et al. (2000): Diesel exhaust, carbon black, and silica particles display distinct Th1/Th2 modulating activity. Toxicol Appl Pharmacol 168: 131-139.

120. Yi L, Wen C, Fan W (2017): Fine particulate matter (PM2.5), a risk factor of rat gestational diabetes with altered blood glucose and pancreatic GLUT2 expression. Gynecol Endocrinol: 1-6. 